\title{
openheart Cardiogenic shock after ST elevation myocardial infarction and IABP- SHOCK II risk score validation in a cohort treated with pharmacoinvasive strategy
}

Pedro Ivo M Moraes, ${ }^{1}$ Claudia Rodrigues Alves, ${ }^{1}$ Marco Tulio Souza, ${ }^{1}$ Suzi Emiko Kawakami, ${ }^{1}$ Iran Goncalves $\mathrm{Jr},{ }^{1}$ Adriano Henrique Pereira Barbosa, ${ }^{1}$ Antonio Celio Moreno, ${ }^{2}$ Adriano Mendes Caixeta, ${ }^{1,3}$ Antonio Carlos Carvalho ${ }^{1}$

\begin{abstract}
- Additional material is published online only. To view please visit the journal online (http://dx.doi.org/10.113/ 6openhrt-2019-001069).
\end{abstract}

To cite: Moraes PIM, Alves CR, Souza MT, et al. Cardiogenic shock after ST elevation myocardial infarction and IABPSHOCK II risk score validation in a cohort treated with pharmacoinvasive strategy. Open Heart 2019;6:e001069. doi:10.1136/ openhrt-2019-001069

Received 18 April 2019 Revised 12 June 2019 Accepted 4 July 2019

Check for updates

(C) Author(s) (or their employer(s)) 2019. Re-use permitted under CC BY-NC. No commercial re-use. See rights and permissions. Published by BMJ.

Discipline of Cardiology Department of Medicine, Federa University of Sao Paulo, Sao Paulo, Brazil

${ }^{2}$ Department of Cardiology, Hospital do Servidor Público Municipal, Sao Paulo, Brazil ${ }^{3}$ Department of Cardiology, Hospital Israelita Albert Einstein, Sao Paulo, Brazil

Correspondence to Dr Pedro Ivo M Moraes; pedroivo_mm@hotmail.com

\section{ABSTRACT}

Objective To validate the Intra-aortic Balloon Pump in Cardiogenic Shock II (IABP-SHOCK II) score in patients with cardiogenic shock after ST elevation myocardial infarction (STEMI) treated with pharmacoinvasive strategy (PhIS) and to analyse the influence of ischaemia time on different risk strata.

Methods We analysed 2143 patients with STEMI who underwent reperfusion with tenecteplase in primary health services between May 2010 and April 2017 and were transferred to a tertiary hospital for cardiac catheterisation and continuity of care. Those who evolved to cardiogenic shock were scored as low (0-2), moderate (3-4) or high (5-9) risk of death in 30 days and pairwise-log-rank test was used to compare strata. Time intervals between symptoms onset and lytic (pain-to-needle) and fibrinolyticcatheterisation were also compared.

Results Cardiogenic shock occurred in 212 (9.9\%) individuals. The 30-day mortality using the IABP-SHOCK II score was $26.6 \%$ for low-risk ( $n=94), 53.2 \%$ for moderate-risk $(n=62)$ and $76 \%$ for high-risk $(n=25)$ analysed patients $(p<0.001)$. Validation of the score showed good discrimination for death, area under the curve of 0.73 (Cl: 0.66 to $0.81 ; p<0.001)$. The median intervals of pain-to-needle and fibrinolytic-catheterisation showed no association with the group stratification (220 vs 251 vs $200 \mathrm{~min} ; \mathrm{p}=0.22$ and 390 vs 435 vs $315 \mathrm{~min}$; $\mathrm{p}=0.18$, respectively).

Conclusions In patients with cardiogenic shock after STEMI treated with PhIS, risk stratification using IABPSHOCK II score was adequate. There was no influence of pain-to-needle and fibrinolytic-catheterisation times on the ability to the score model stratification.

\section{INTRODUCTION}

In a high-severity scenario such as cardiogenic shock after acute ST elevation myocardial infarction (STEMI), hospital mortality rates reach $50 \%$, even after adequate reperfusion. ${ }^{1-3}$ Immediate risk stratification offers

\section{Key questions}

What is already known about this subject?

- Risk stratification models in patients with cardiogenic shock after ST elevation myocardial infarction (STEMI) are well recognised in the literature, particularly in patients undergoing primary percutaneous coronary intervention.

What does this study add?

- The study contributes to the validation of a risk stratification model in the specific setting of pharmacoinvasive strategy (PhIS), a scenario that is relatively underexplored. The results also incorporate an epidemiological knowledge about cardiogenic shock.

How might this impact on clinical practice?

- In a high-severity scenario such as cardiogenic shock after STEMI, risk stratification offers important prognostic information and may aid to selection of patients for advanced therapies. Our findings reveal that, particularly in a population treated with $\mathrm{PhIS}$, the simple-to-use Intra-aortic Balloon Pump in Cardiogenic Shock II score is suitable.

important prognostic information and may direct the selection of patients for advanced therapies such as mechanical ventricular assistance and cardiac transplantation. ${ }^{4-9}$

Although primary percutaneous coronary intervention (PPCI) is the ideal strategy for reperfusion, the similarity between pharmacoinvasive strategy (PhIS) and PPCI has been recently demonstrated in patients without shock up to 3 hours after the onset of symptoms. ${ }^{10}$ Based on multiple data, PhIS has been considered a valuable and effective alternative in patients who cannot reach early access to a cardiac catheterisation laboratory and it was incorporated into 
Table 1 Variables of the Intra-aortic Balloon Pump in Cardiogenic Shock II score

\begin{tabular}{ll}
\hline Variable & Points \\
\hline Age $>73$ years & 1 \\
History of stroke & 2 \\
TIMl flow grade $<3$ after $\mathrm{PCl}$ & 2 \\
Glucose $>191 \mathrm{mg} / \mathrm{dL}$ & 1 \\
Arterial lactate $>45 \mathrm{mg} / \mathrm{dL}(>5 \mathrm{mmol} / \mathrm{L})$ & 2 \\
Creatinine $>1.5 \mathrm{mg} / \mathrm{dL}$ & 1 \\
Maximum & 9 \\
\hline
\end{tabular}

$\mathrm{PCl}$, percutaneous coronary intervention; TIMI, Thrombolysis In Myocardial Infarction.

guidelines. ${ }^{10-18}$ On the other hand, PhIS in cardiogenic shock has only recently been formally considered when PPCI is not available. ${ }^{18}$ In developing countries, PhIS to patients with cardiogenic shock has been applied more often and the analysis of this population may fill gaps of knowledge on this subject.

A new and simple risk score (table 1), derived from the Intra-aortic Balloon Pump in Cardiogenic Shock II (IABPSHOCK II Trial), ${ }^{19}$ was developed and validated for 30-day risk of death stratification in patients with cardiogenic shock secondary to STEMI who undergo PPCI. Several demographic characteristics and the metrics of STEMI care differentiate patients receiving PPCI or PhIS. ${ }^{20}{ }^{21}$

This study aimed to validate the IABP-SHOCK II score in a cohort of patients with cardiogenic shock secondary to STEMI treated according to a PhIS and examined the influence of ischaemia time on the different risk strata.

\section{METHODS}

A total of 2143 patients with STEMI who underwent reperfusion with tenecteplase (TNK) between May 2010 and April 2017 in primary health services and were transferred to a tertiary hospital (hub-and-spoke model), as previously reported. ${ }^{16}{ }^{17}$ Patients who progressed to cardiogenic shock due to primary ventricular failure within the first 12 hours of symptom onset, including those with signs of circulatory collapse prior to TNK administration, were included in this report. Cardiogenic shock was defined by the presence of classic clinical signs of organ hypoperfusion, sustained systolic blood pressure $<90 \mathrm{~mm} \mathrm{Hg}$ or need for vasoactive drugs.

In the development of the IABP-SHOCK II score, six variables were identified for stratification of the groups: age $>73$ years, history of stroke, blood glucose $>191 \mathrm{mg} /$ $\mathrm{dL}$, creatinine $>1.5 \mathrm{mg} / \mathrm{dL}$, arterial lactate $>45 \mathrm{mg} / \mathrm{dL}$ and Thrombolysis in Myocardial Infarction (TIMI) flow after coronary angioplasty $<3$. The scoring system gave one or two points for each variable based on the observed HR ranging from 0 to 9 points (table 1 ) ${ }^{19}$ Patients were scored as low (0-2 points), moderate (3-4 points) and high risk (5-9 points) of death in 30 days, and the pairwise-log-rank test was used to compare death rates among strata. The area under the curve (AUC) was used to analyse the accuracy of the score, and the receiver operating characteristic curve was used to evaluate the efficiency of the variables for discrimination of death.

Time between onset of symptoms and administration of a fibrinolytic agent (pain-to-needle time) and time between thrombolytic infusion and cardiac catheterisation (fibrinolytic-catheterisation time) were compared in relation to the different strata.

\section{STEMI patients treated with PhIS}
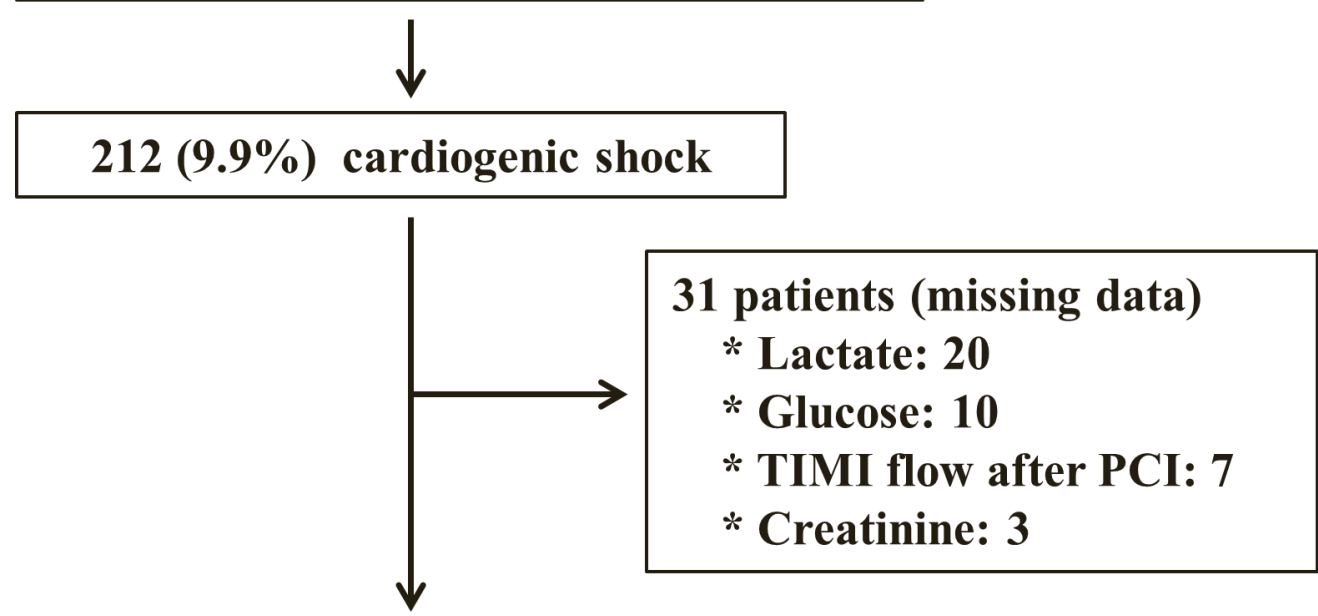

\section{1 patients (validation cohort)}

Figure 1 Validation cohort of patients with cardiogenic shock after STEMI treated with PhIS. PCI, percutaneous coronary intervention; PhIS, pharmacoinvasive strategy; STEMI, ST elevation myocardial infarction; TIMI, Thrombolysis In Myocardial Infarction. 


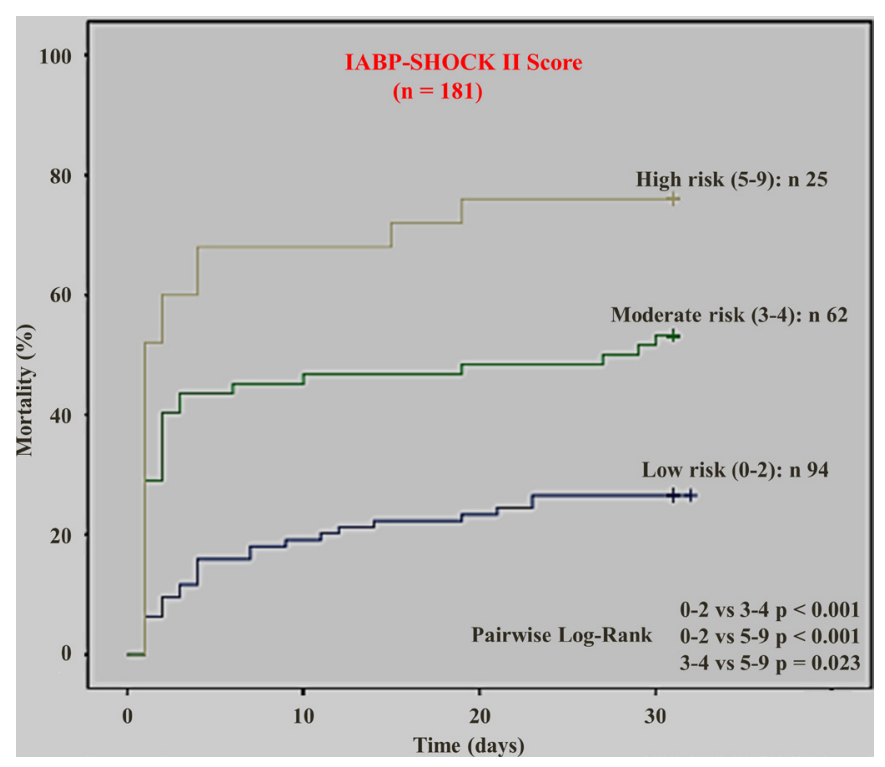

Figure 2 Kaplan-Meier analysis for 30-day mortality according to the score stratification in patients with cardiogenic shock after ST elevation myocardial infarction treated with pharmacoinvasive strategy. IABP-SHOCK II, Intra-aortic Balloon Pump in Cardiogenic Shock II.

The categorical variables were compared with the $\chi^{2}$ test and the continuous variables with Student's t-test and the Mann-Whitney test. The Kruskal-Wallis test was used to compare continuous variables in three distinct groups when the normality assumption was not met. SPSS V.22.0 was used for statistical analysis. A value of $\mathrm{p}<0.05$ was considered statistically significant.

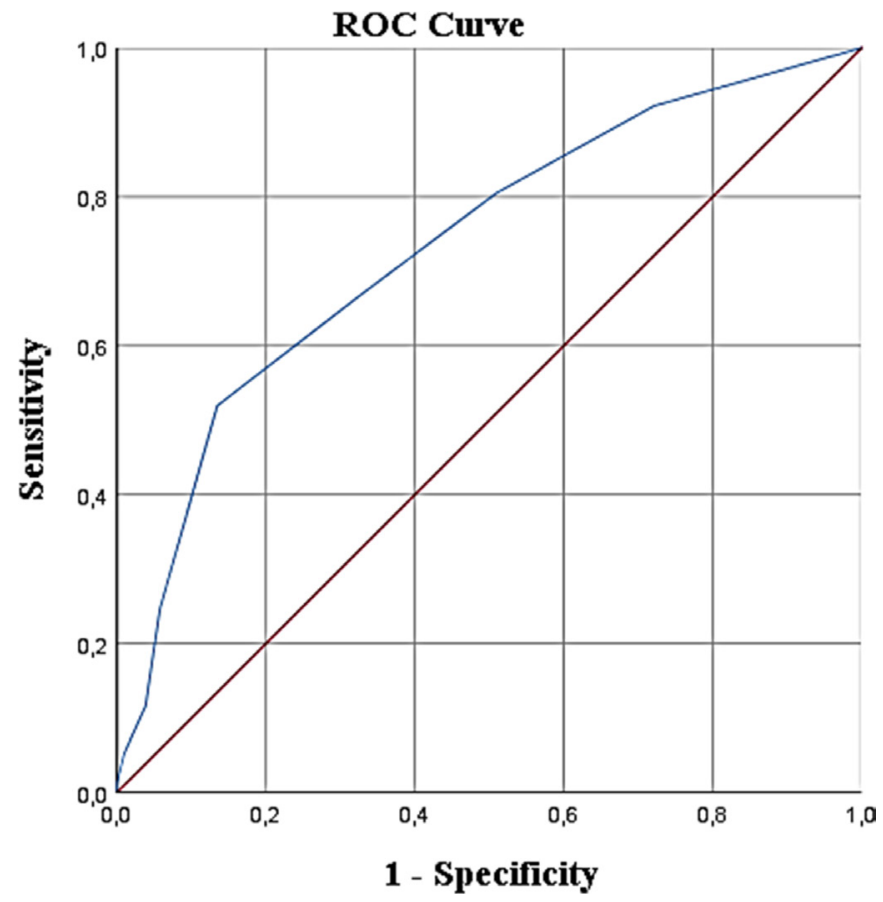

Figure 3 ROC curve Intra-aortic Balloon Pump in Cardiogenic Shock II score. ROC, receiver operating characteristic.

\section{RESULTS}

Out of 2143 patients diagnosed with STEMI treated with PhIS, 212 (9.9\%) developed cardiogenic shock. In all, 31 patients $(14.6 \%)$ with incomplete data were excluded from the analysis, and the validation cohort included remaining 181 patients. Mortality rates were similar between the analysed and excluded patients $(42.5 \%$ and $45.1 \%$, respectively, $\mathrm{p}=0.77$ ) (figure 1 ).

The median age was 61 years, with IQR 53-71 years, $134(63.2 \%)$ were men, $144(67.9 \%)$ had systemic arterial hypertension, $111(52.3 \%)$ were current or previous smokers, $106(50 \%)$ had hypercholesterolaemia, 87 (41\%) had diabetes mellitus and $14(6.6 \%)$ had a previous stroke. The mean ejection fraction by echocardiogram was $38 \%$ and the overall use of IABP was $55.2 \%$.

In this validation cohort, $94(51.9 \%)$ were classified as low risk, $62(34.2 \%)$ as moderate risk and 25 (13.9\%) as high risk. The 30-day mortality in the three strata using the IABP-SHOCK II score was $26.6 \%, 53.2 \%$ and $76 \%$, respectively. Comparison between groups using a Kaplan-Meier curve (figure 2) with the pairwise log-rank test showed good discrimination (low vs moderate risk, $\mathrm{p}<0.001$ and moderate vs high risk, $\mathrm{p}=0.029)$.

The overall 30-day mortality was $42.5 \%(\mathrm{~N}=77)$, showing adequate predictive value of the score with an AUC of 0.73 (95\% CI: 0.66 to $0.81 ; \mathrm{p}<0.001$ ) (figure 3 ).

Pain-to-needle time was significantly longer in patients who died (251 min IQR $140-528$ vs $210 \mathrm{~min}$, IQR 130-343 min, $p=0.032$ ). However, there was no difference between group stratification with the IABP-SHOCK II score and the median pain-to-needle time and fibrinolytic-catheterisation time according to $(\mathrm{p}=0.22$ and $\mathrm{p}=0.18$, respectively) table 2 .

Furthermore, the AUC showed adequate accuracy for TIMI coronary flow $<3$ after angioplasty in the differentiation between low-risk (AUC $0.76,95 \%$ CI: 0.66 to 0.83 , $\mathrm{p}<0.001$ ), moderate-risk (AUC $0.65,95 \%$ CI: 0.56 to 0.73 , $\mathrm{p}<0.001$ ) and high-risk groups (AUC $0.76,95 \% \mathrm{CI}: 0.67$ to $0.86, p<0.001$ ), indicating that this variable maintained discriminatory scoring capacity despite the use of fibrinolytic agents.

\section{DISCUSSION}

Our study demonstrated the validity of the IABP-SHOCK II score in a population of patients with cardiogenic shock after STEMI treated with a PhIS. Both the mortality rate and the ability to predict risk of death in this cohort were equivalent to those in the original cohort of patients treated with PPCI from which the score was derived. ${ }^{19}$

PPCI treatment is the most effective reperfusion method for myocardial salvage in patients with STEMI, especially in the most severe cases, allowing faster and more complete reperfusion in late comers or in the presence of cardiogenic shock. ${ }^{18}$ However, PhIS in cardiogenic shock is a reality in patients without immediate haemodynamic instability or places with a delay in access to a cardiac catheterisation laboratory, especially 
Table 2 Comparison of pain-to-needle and fibrinolytic-catheterisation intervals in relation to groups stratified by the score

\begin{tabular}{|c|c|c|c|c|}
\hline & \multicolumn{4}{|c|}{ Intra-aortic Balloon Pump in Cardiogenic Shock II score } \\
\hline & Low & Intermediate & High & \\
\hline & $(\mathrm{N}=94)$ & $(\mathrm{N}=62)$ & $(\mathrm{N}=62)$ & $P$ value \\
\hline Pain-to-needle & 220 & 251 & 200 & 0.22 \\
\hline (Median in minutes) & IQR 135-392 & IQR 150-495 & IQR 120-378 & \\
\hline Pain-to-needle $<3$ hours & $40(42.5 \%)$ & $23(37.1 \%)$ & $11(44.0 \%)$ & 0.85 \\
\hline Fibrinolytic-catheterisation & 390 & 435 & 315 & 0.18 \\
\hline (Median in minutes) & IQR 280-713 & IQR 280-820 & IQR 232-557 & \\
\hline
\end{tabular}

in developing countries and rural areas. The experience of previous randomised trials including only patients with short pain-to-needle times is hardly transferred to clinical practice where the same socioeconomic factors that hamper access to PPCI increase ischaemic times. ${ }^{15} 17$

Clearly, as the time for administration increases, the efficacy of fibrinolytic agents in PhIS is reduced, and this fact may affect not only mortality rates but also TIMI 3 coronary flow rates after angioplasty. ${ }^{22}$ However, the AUC in the different strata of our population showed adequate accuracy of TIMI coronary flow $<3$ after angioplasty, indicating that this variable maintains adequate discriminatory capacity for scoring mechanical reperfusion and was not influenced by pre-PCI flow or by the delay in reaching the catheterisation laboratory (more than 6 hours).

As expected, the time between onset of symptoms and administration of a fibrinolytic agent (pain-to-needle time) was significantly longer in patients who died. However, pain-to-needle and fibrinolytic-catheterisation times were not associated with the group stratification using the IABP-SHOCK II score. This finding may be explained by the potential of these variables to be more closely associated with the development of cardiogenic shock in patients with STEMI treated with PhIS, and to be less associated with progression to death when the patient is already in shock.

The need for early identification of patients with cardiogenic shock and a higher risk of death than usual is obvious, since early intervention could prevent an unfavourable outcome. In addition, the validation of an easyto-use risk score has the potential to become a very useful tool for emergency physicians and intensivists, especially when delays in standard ideal treatments may impact outcomes.

\section{CONCLUSIONS}

The IABP-SHOCK II score is suitable for 30-day riskof-death stratification in patients with cardiogenic shock secondary to STEMI treated with PhIS. Although prolonged pain-to-needle time was associated with higher mortality, there was no influence of pain-to-needle and fibrinolytic-catheterisation times on the ability to the score model stratification.

\section{Limitations of the study}

Although data were collected prospectively, this was a retrospective analysis of a cohort that originated from a single tertiary STEMI(online supplementary file 1) treatment centre. Since all patients received TNK, our results do not necessarily apply to populations using other types of fibrinolytic agents or different PhIS models (non-systematic cardiac catheterisation or different time intervals for cardiac catheterisation or fibrinolytic infusion). The exclusion of 31 of the 212 patients (14.6\%) with cardiogenic shock is a limitation mitigated by the fact that mortality was not significantly different between the excluded group and the validation cohort used for scoring.

Contributors ACC and PIM conceived of the presented idea. PIM and CRA developed the theory and performed the computations. MTS, SEK, AMC, AHPB, IGJ and ACM contributed to data collect and a critical review of the abstract. All authors discussed the results and contributed to the final manuscript.

Funding The authors have not declared a specific grant for this research from any funding agency in the public, commercial or not-for-profit sectors.

Competing interests None declared.

Patient consent for publication Not required.

Provenance and peer review Not commissioned; externally peer reviewed.

Data availability statement Data are available upon reasonable request.

Open access This is an open access article distributed in accordance with the Creative Commons Attribution Non Commercial (CC BY-NC 4.0) license, which permits others to distribute, remix, adapt, build upon this work non-commercially, and license their derivative works on different terms, provided the original work is properly cited, appropriate credit is given, any changes made indicated, and the use is non-commercial. See: http://creativecommons.org/licenses/by-nc/4.0/.

\section{REFERENCES}

1. Kolte D, Khera S, Aronow WS, et al. Trends in incidence, management, and outcomes of cardiogenic shock complicating ST-elevation myocardial infarction in the United States. J Am Heart Assoc 2014;3:e000590.

2. Goldberg RJ, Spencer FA, Gore JM, et al. Thirty-year trends (1975 to 2005) in the magnitude of, management of, and hospital death rates associated with cardiogenic shock in patients with acute myocardial infarction: a population-based perspective. Circulation 2009;119:1211-9.

3. Aissaoui N, Puymirat E, Tabone X, et al. Improved outcome of cardiogenic shock at the acute stage of myocardial infarction: a report from the USIK 1995, USIC 2000, and FAST-MI French nationwide registries. Eur Heart J 2012;33:2535-43.

4. Katz JN, Stebbins AL, Alexander JH, et al. Predictors of 30-day mortality in patients with refractory cardiogenic shock following 
acute myocardial infarction despite a patent infarct artery. Am Heart J 2009;158:680-7.

5. Sutton AGC, Finn P, Hall JA, et al. Predictors of outcome after percutaneous treatment for cardiogenic shock. Heart 2005;91:339-44

6. Klein LW, Shaw RE, Krone RJ, et al. Mortality after emergent percutaneous coronary intervention in cardiogenic shock secondary to acute myocardial infarction and usefulness of a mortality prediction model. Am J Cardiol 2005;96:35-41.

7. Garcia-Alvarez A, Arzamendi D, Loma-Osorio P, et al. Early risk stratification of patients with cardiogenic shock complicating acute myocardial infarction who undergo percutaneous coronary intervention. Am J Cardiol 2009;103:1073-7.

8. Sleeper LA, Reynolds HR, White HD, et al. A severity scoring system for risk assessment of patients with cardiogenic shock: a report from the shock trial and registry. Am Heart J 2010;160:443-50

9. Pöss J, Desch S, Thiele H. Shock management in acute myocardial infarction. Eurolntervention 2014;10 Suppl T:T74-T82.

10. Armstrong PW, Gershlick AH, Goldstein P, et al. Fibrinolysis or primary $\mathrm{PCl}$ in ST-segment elevation myocardial infarction. $N$ Engl J Med 2013;368:1379-87.

11. Di Mario C, Dudek D, Piscione F, et al. Immediate angioplasty versus standard therapy with rescue angioplasty after thrombolysis in the combined abciximab reteplase stent study in acute myocardial infarction (CARESS-in-AMI): an open, prospective, randomised, multicentre trial. Lancet 2008;371:559-68.

12. Danchin N, Coste $\mathrm{P}$, Ferrières $\mathrm{J}$, et al. Comparison of thrombolysis followed by broad use of percutaneous coronary intervention with primary percutaneous coronary intervention for ST-segmentelevation acute myocardial infarction: data from the French registry on acute ST-elevation myocardial infarction (FAST-MI). Circulation 2008;118:268-76.
13. Cantor WJ, Fitchett D, Borgundvaag B, et al. Routine early angioplasty after fibrinolysis for acute myocardial infarction. $N$ Engl J Med 2009;360:2705-18.

14. Fernández-Avilés F, Alonso JJ, Peña G, et al. Primary angioplasty vs. early routine post-fibrinolysis angioplasty for acute myocardial infarction with ST-segment elevation: the GRACIA-2 non-inferiority, randomized, controlled trial. Eur Heart J 2007;28:949-60.

15. Elguindy AM. Lessons from the trials stream and FAST-MI Pharmacoinvasive therapy: a continued role for fibrinolysis in the primary $\mathrm{PCl}$ era.

16. Caluza ACV, Barbosa AH, Gonçalves I, et al. Rede de infarto com supradesnivelamento de ST: sistematização em 205 casos diminui eventos clínicos Na rede pública. Arq Bras Cardiol 2012;99:1040-8.

17. Ferreira GM, Moraes PIM, Carvalho AC, et al. St segment elevation myocardial infarction (STEMI) network sustains low hospital mortality throughout the years in an emerging country location. Eur Heart $J$ 2014;35:1173-4.

18. Ibanez B, James S, Agewall S, et al. 2017 ESC guidelines for the management of acute myocardial infarction in patients presenting with ST-segment elevation. Eur Heart J 2018;39:119-77.

19. Pöss J, Köster J, Fuernau G, et al. Risk Stratification for Patients in Cardiogenic Shock After Acute Myocardial Infarction. J Am Coll Cardiol 2017;69:1913-20.

20. Boden WE, Eagle K, Granger CB. Reperfusion strategies in acute ST-segment elevation myocardial infarction. J Am Coll Cardiol 2007;50:917-29.

21. Abbott JD. Pharmacoinvasive strategy for ST-segment elevation myocardial infarction: wading through the treatment options. Circ Cardiovasc Interv 2010;3:294-6.

22. Boersma E, Maas AC, Deckers JW, et al. Early thrombolytic treatment in acute myocardial infarction: reappraisal of the golden hour. Lancet 1996;348:771-5. 